\title{
The effect of undernutrition in the early postnatal period on skeletal muscle tissue
}

\author{
BY STEPHANIE S. WARD AND NEIL C. STICKLAND \\ Department of Veterinary Basic Sciences, The Royal Veterinary College, Royal College Street, \\ London NWI OTU
}

(Received 17 June 1991-Accepted 12 March 1992)

\begin{abstract}
Guinea-pigs were undernourished from birth by first, cross-fostering in groups of six (in pairs for control animals) and then by feeding a diet of $60 \%$ of ad lib. intake from 2 to 6 weeks. The changing characteristics of muscle fibre types in the biceps brachii and soleus muscles were monitored by histochemistry. Undernutrition appeared to delay maturation of muscle fibres. Fibre cross-sectioned area was reduced in all fibres of the $60 \%$ of ad lib. intake group. Fibres of the biceps brachii were more affected than those of the soleus. Fibre area vulnerability was partly associated with a high relative growth rate in biceps brachii at this time. Total protein content in the semitendinosus muscle was depressed in the undernourished group compared with the control group. DNA concentrations were initially higher in the control group but decreased in both groups to similar levels by 6 weeks. RNA concentration increased up to 5 weeks in the control group and then decreased, but decreased after 2 weeks in the undernourished group.
\end{abstract}

Muscle: Undernutrition: Differentiation

In the early postnatal period muscles are transformed from immature into efficiently adapted units. Expression of neonatal and foetal myosin isoforms are suppressed while adult ones are enhanced (Gauthier et al. 1978, 1982). The increased sarcomere-shortening velocity in fast-twitch muscles, which is correlated with calcium-activated ATPase (EC 3.6.1.32) (Barany, 1967), leads to a concurrent rise in glycolytic metabolism and a decrease in oxidative metabolism (Goldspink, 1962; Baldwin et al. 1978). Slow-twitch muscles, on the other hand, become increasingly oxidative and retain low sarcomereshortening velocities (Close, 1964; Drachman \& Johnson, 1973). Decrease in fast-type myosins can be monitored by the loss of stability at an alkaline $\mathrm{pH}$ in myosin ATPase histochemistry (Goldspink \& Ward, 1979).

Alterations in metabolic profile are thought to be mediated through fibre size (Goldspink \& Howells, 1974; Swatland, 1983). Myosin transformations are the result of nervous intervention (Engel \& Kaparti, 1968; Butler-Browne \& Whalen, 1984) and hormonal signalling, particularly via thyroxine (Baldwin et al. 1978; Ianuzzo et al. 1980). Conditions which upset the normal controlling processes would be expected to disrupt the course of differentiation in the muscle.

The effect of undernutrition on mature muscle (i.e. following the fibre hyperplastic phase) has generally been found to be reversible (Goldspink \& Ward, 1979). The main effect is a reduction in fibre size (Stickland et al. 1975; Goldspink \& Ward, 1979) which is mediated by a depression in protein synthesis (Winick \& Nobel, 1966). The proportion of fibre types has been found to be unaffected by undernutrition imposed on mature animals (Goldspink \& Ward, 1979). In animals experiencing dietary restriction prenatally, however, there is evidence that fibre-type proportions may be altered in the adult (Howells et al. 1978; Bedi 
et al. 1982). The effect of dietary restriction on skeletal muscle tissue in the early postnatal period has not been comprehensively studied. The present study was designed to investigate the possibility that undernutrition confined to the period of postnatal muscle differentiation may affect the transitional maturation of muscle fibre types.

\section{MATERIALS AND METHODS}

\section{Animals}

Thirty-six neonatal guinea-pigs (weighing over $50 \mathrm{~g}$ ) and lactating females were obtained from Tuck and Son, Battlesbridge, Essex. The animals were divided into two equal groups. The first was fostered in pairs with one lactating female, and the second was fostered in groups of six per female. This procedure ensured that the second group was undernourished compared with the first group from birth to weaning.

Weaning for all animals was at 2 weeks postnatally at which time the young were housed separately and fed on solid food. The group which had been in large lactation units was restricted to a diet of $60 \%$ of ad lib. intake which was measured daily against the other group, the individuals of which acted as pair-fed controls. The diet used was the commercial SG1 pellet (Quest Nutrition, Canterbury, Kent). The diet was supplemented with vitamin $E$ (Roche) at a concentration of $60 \mathrm{mg} \alpha$-tocopherol $/ \mathrm{kg}$ diet. Three animals from each group were killed at weekly intervals from 1 to 6 weeks of age (using an intraperitoneal injection of sodium pentobarbitol). Various body measurements were taken including weights of body, liver and brain and lengths of humerus and tibia. From each animal biceps brachii, soleus and semitendinosus muscles were removed, weighed and used for further analysis.

\section{Histochemistry}

The biceps brachii and soleus muscles were chosen for histochemical analysis since they represent fast- and slow-twitch muscles respectively. Frozen sections $(10 \mu \mathrm{m})$ were taken from the mid-belly of each muscle and processed for the following three histochemical techniques: (1) myosin ATPase (EC 3.6.1.32) with pre-incubation at either $\mathrm{pH} 10.6$ (BATPase) or pH 4.6 (AATPase) (Guth \& Samaha, 1970), (2) succinate dehydrogenase (SDH; EC 1.3.99.1) (Nachlas et al. 1957) and (3) glycogen phosphorylase (GP; $E C$ 2.4.1.1) (Takeuchi, 1956). Fibres were classified as positive or negative (and, in some cases, intermediate) for each reaction. Proportional counts of fibre 'types' were based on analysis of approximately 100 fibres for each muscle sample. Samples were also taken from three newborn animals for this analysis.

\section{Fibre size}

Fibre area estimations were made on frozen sections using 100 fibres of each type and from each muscle. Measurements were performed on a digital pad attached to a computer package (VIDS; Analytical Measuring Systems Ltd, Saffron Walden, Essex).

\section{Biochemistry}

Protein and nucleic acid content was estimated for the semitendinosus muscles. Samples were taken from the middle two-thirds of the muscle.

$R N A$ and DNA. Nucleic acids were extracted using a modified Schmidt Thannauser method (Munro \& Fleck 1966), with RNA and DNA concentrations being calculated from absorbance measurements at wavelengths 260 and $268 \mathrm{~nm}$ respectively.

Protein. Concentrations were estimated by the method of Wigmore (1982), based on those of Helander (1957) and Millward (1970). Protein was separated into sarcoplasmic 
and fibrillar fractions using salt extraction. A commercial dye reagent (Biorad) was added to the extractions and readings were taken from a spectrophotometer (LKB) at $595 \mathrm{~nm}$. Protein concentration was then calculated using a standard curve of bovine serum albumin.

RESULTS

Gross body variables

Measurements on gross body variables served to illustrate that both the cross-fostering technique (up to 2 weeks) and the $60 \%$ of ad lib. intake dietary regimen (2-6 weeks) was exerting a significant effect on body growth (Fig. 1). Body weight was increasingly affected in the undernourished animals over the 6 week period. By 6 weeks the percentage difference from the control was 35 (Student's $t$ test; $P<0.05$ ). Liver weight was reduced by $40 \%$ $(P<0.001)$, whereas brain weight was not significantly different. Bone lengths were also reduced (tibia by $11 \%$ and humerus by $15 \%$ ).

\section{Muscle fibre size}

Biceps brachii. A paired $t$ test revealed that, on average, the positive BATPase fibres were $46 \%$ smaller $(P<0.001)$ and the negative BATPase fibres were $35 \%(P<0.005)$ smaller in the undernourished group.

Soleus. Both BATPase positive and negative fibres were on average $27 \%$ smaller in the $60 \%$ of ad lib.-fed animals $(P<0.01)$.

It is thought that the degree to which tissues and organs are affected by undernutrition is dependent on their relative growth rate at the time of dietary restriction. For this reason logarithmic regressions of fibre area $v$. body weight were calculated. If fibre area $(Y)$ is increasing in line with body weight $(X)$ then the expected relationship is $Y=K . X^{0 \cdot 66}$. The regression coefficients were, therefore, compared with 0.66 (Table 1 ).

It can be seen from Table 1 that both muscles studied had a high relative growth rate in ad lib. situations. This growth rate was largely reduced by restricted nutrition. The implication from this finding is that muscle tissue is more affected by undernutrition than overall body weight.

\section{Histochemistry}

Biceps brachii. (1) Myosin ATPase. The number of negative BAPTPase fibres was counted in the deep region of the muscle and expressed as a percentage of the total number in the deep area. There was no change in the ratio of fibres with age and there was no significant difference between the groups (ad lib. 12.2\%, 60\% of ad lib. intake 12.4\%).

(2) $S D H$. Fibres were classified as positive, intermediate or negative for the reaction. In the superficial area of the muscle all fibres were positive until 2 weeks of age in the $a d$ lib.fed group and 4 weeks in the undernourished when there was a swift transition to $60 \%$ negative in the ad lib.-fed animals (Plate 1) and $55 \%$ in the restricted group. The difference between the two groups was not significant.

In the deep area of the muscles the number of positive fibres remained constant with age and formed about $75 \%$ in both groups. The remaining $25 \%$ were intermediate fibres until 3 weeks in the $a d l i b$. and 5 weeks in the restricted group. About half the intermediate fibres then became negative leaving approximately $12 \%$ intermediate fibres in the deep area of the muscle. These intermediate fibres corresponded to the negative BATPase fibres in this area. They could now be classified as slow oxidative (Peter et al. 1972).

(3) GP. GP staining was inversely related to SDH staining. There was no staining at all for the initial postnatal period until the appearance of the first SDH negative fibres. The biceps then rapidly became increasingly GP positive. 


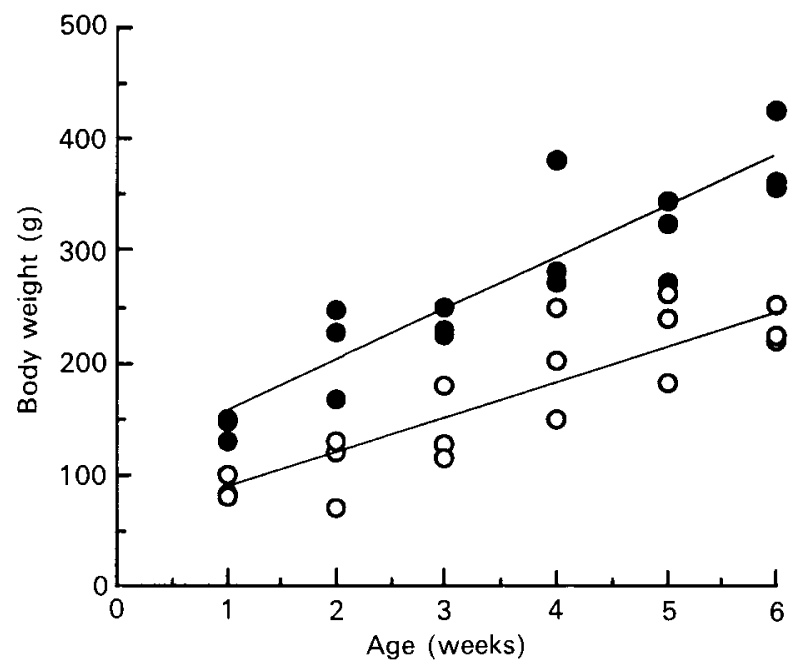

Fig. 1. Body weights of all guinea-pigs used in the study. Computed regression lines are shown for each group. ( ), Control group; $(O), 60 \%$ of ad lib.-fed group. For details of dietary regimen, see p. 142.

Table 1. Regression coefficients for the relationship between fibre cross-sectioned area and body weight in guinea-pigs fed ad lib., or at $60 \%$ ad lib. intake*

(Mean values with their standard errors)

\begin{tabular}{|c|c|c|c|c|c|c|c|}
\hline \multirow[b]{4}{*}{ Muscle fibre type } & \multicolumn{4}{|c|}{$b$} & \multirow{4}{*}{$\begin{array}{c}\text { Statistical } \\
\text { significance of } \\
\text { difference } \\
\text { between } \\
\text { groups: } P<\end{array}$} & \multirow{2}{*}{\multicolumn{2}{|c|}{$\begin{array}{c}\text { Statistical significance of } \\
\text { difference from } \\
0.66: P<\end{array}$}} \\
\hline & \multirow{2}{*}{\multicolumn{2}{|c|}{ Ad lib. }} & \multirow{2}{*}{\multicolumn{2}{|c|}{$\begin{array}{c}60 \% \\
\text { ad lib. }\end{array}$}} & & & \\
\hline & & & & & & & $60 \%$ of \\
\hline & Mean & $\mathrm{SE}$ & Mean & $\mathrm{SE}$ & & Ad lib. & ad lib. \\
\hline \multicolumn{8}{|l|}{ Biceps } \\
\hline BATPase + & 0.94 & $0 \cdot 3$ & 0.92 & 0.1 & NS & 0.025 & 0.005 \\
\hline BATPase- & $1 \cdot 23$ & 0.2 & 0.65 & 0.4 & $0-001$ & 0.001 & NS \\
\hline $\begin{array}{l}\text { Statistical significance of } \\
\text { difference between } \\
\text { BATPase }+ \text { and } \\
\text { BATPase }-: P<\end{array}$ & \multicolumn{2}{|c|}{0.05} & \multicolumn{2}{|c|}{0.05} & & & \\
\hline \multicolumn{8}{|l|}{ Soleus } \\
\hline BATPase + & 1.0 & $0 \cdot 4$ & $0 \cdot 61$ & $0 \cdot 27$ & $0 \cdot 01$ & 0.001 & NS \\
\hline BATPase- & 0.85 & $0 \cdot 19$ & $0 \cdot 5$ & 0.26 & 0.005 & $0 \cdot 05$ & NS \\
\hline $\begin{array}{l}\text { Statistical significance of } \\
\text { difference between } \\
\text { BATPase }+ \text { and } \\
\text { BATPase }-: P<\end{array}$ & \multicolumn{2}{|c|}{$0 \cdot 05$} & \multicolumn{2}{|c|}{ NS } & & & \\
\hline
\end{tabular}

BATPase, myosin ATPase (EC 3.6.1.32) pre-incubated at $\mathrm{pH} 10 \cdot 6$; NS, not significant.

* For details of dietary regimen, see p. 142 .

Soleus. (1) Myosin ATPase. The soleus had a mixed population of fibres at birth in terms of their staining with myosin ATPase. The number of positive BATPase fibres was constant at approximately $45 \%$ between birth and 2 weeks of age and then fell steadily to 6 weeks postnatally (Fig. 2). There was no difference between the nutritional groups in the rate of 

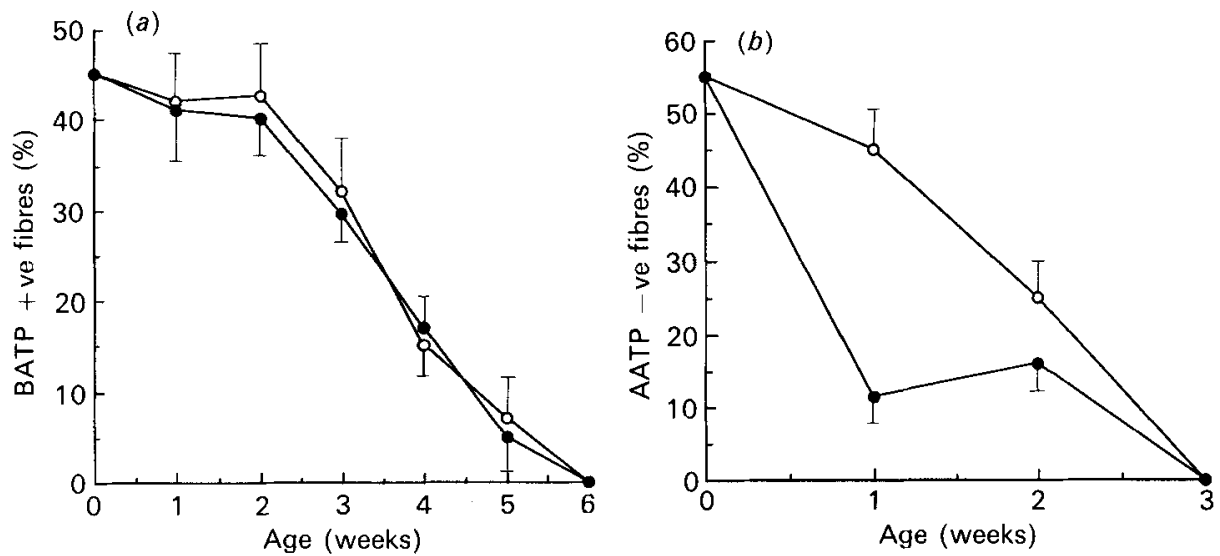

Fig. 2. Disappearance of immature reactions with ATPase (EC 3.6.1.32) histochemistry in the soleus muscle of guinea-pigs. (a) Positive ATPase pre-incubated at pH 10.6 (BATPase) fibres; (b) negative ATPase pre-incubated at $\mathrm{pH} 4.6$ (AATPase) fibres. Points represent the means with their standard errors represented by vertical bars for three animals. (O), Control; $(\bigcirc), 60 \%$ of ad lib.-fed group. For details of dietary regimen, see p. 142.

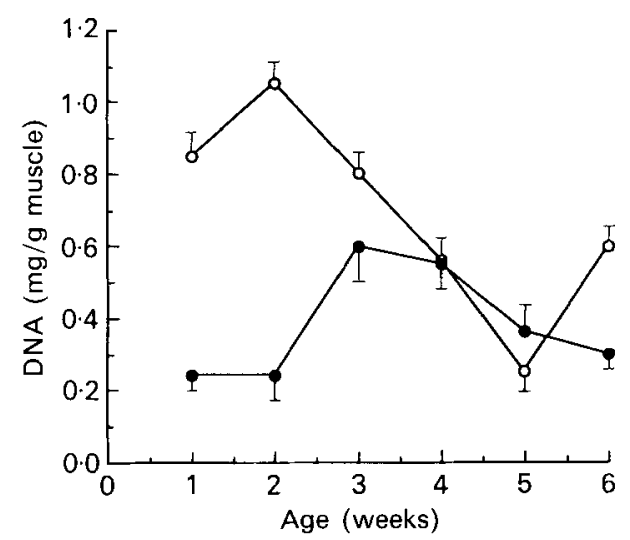

Fig. 3. Concentration of DNA extracted from the semitendinosus muscle of guinea-pigs. Points represent the means with their standard errors represented by vertical bars for three animals. (O), Control; $(0), 60 \%$ of ad lib.fed group. For details of dietary regimen, see p. 142.

disappearance of these fibres. Negative AATPase fibres also fell with age, such that from an average of $55 \%$ at birth there were none by 3 weeks postnatally (Fig. 4). Initially the number fell more rapidly in the control group so there were less AATPase negative fibres than the undernourished muscle at 1 week $(P<0.001)$. At 2 weeks, however, the number of AATPase negative fibres was similar in the two groups.

The immature fibres were the smallest in the muscle so that the negative AATPase and positive BATPase populations were overlapping. The adult muscle was $100 \%$ BATPase negative and AATPase positive.

(2) $S D H$. There was no change in the SDH staining pattern with age. In both groups fibres remained $100 \%$ intermediate.

(3) GP. The muscle fibres were very weakly positive and corresponded to the number of BATPase positive fibres present. 


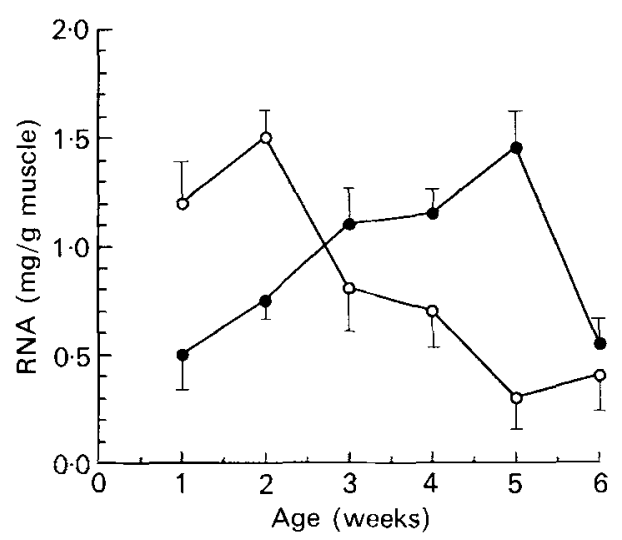

Fig. 4. Concentration of RNA extracted from the semitendinosus muscle of guinea-pigs. Points represent means with their standard errors represented by vertical bars for three animals. (O), Control; $(\bigcirc), 60 \%$ of ad lib.-fed group. For details of dietary regimen, see p. 142.
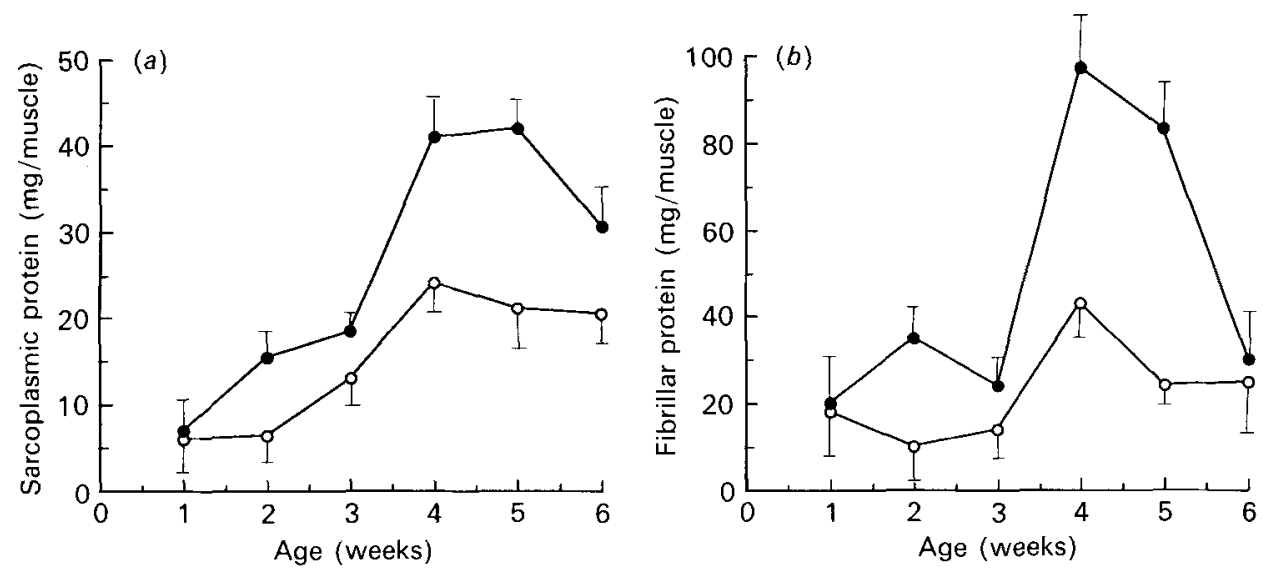

Fig. 5. Protein extracted from the semitendinosus muscle. (a) Total fibrillar protein per muscle; $(b)$ total sarcoplasmic protein per muscle. Points represent the means with their standard errors represented by vertical bars for three animals. (O), Control; (O), 60\% of ad lib.-fed group. For details of dietary regimen, see p. 142.

\section{Biochemistry}

Nucleic acids and protein fractions were expressed as concentrations throughout the postnatal period under study. Protein fractions were also expressed as total amounts per muscle. The results are shown in Figs. 3-5. Generally, the tendency in control animals was for concentration of all variables to increase initially during growth with DNA declining after about 4 weeks (Fig. 3), and all other variables declining after 5 weeks (Figs. 4 and 5).

In the $60 \%$ of ad lib.-fed group, concentrations of DNA and RNA fell with age after 2 weeks (Figs. 3 and 4). There was no demonstrable difference between the nutritional groups in protein concentrations but total amounts of both sarcoplasmic and fibrillar fractions were reduced in the undernourished muscles (Fig. 5). Ratios that have been commonly used to reveal nutritional effects on variables associated with protein synthesis were calculated for each age. Differences were investigated using a paired $t$ test. The results (Table 2) showed a difference between nutritional groups for RNA:DNA and for protein:DNA ratios but not for the sarcoplasmic:fibrillar protein ratios. None of the ratios showed any 
Table 2. Mean values for ratios of biochemical variables associated with protein synthesis in guinea-pigs fed ad lib. or at $60 \%$ of ad lib. intake*

(Mean values with their standard errors)

\begin{tabular}{|c|c|c|c|c|c|c|}
\hline \multirow[b]{2}{*}{ Dietary regimen } & \multicolumn{2}{|c|}{ RNA:DNA } & \multicolumn{2}{|c|}{ Protein:DNA } & \multicolumn{2}{|c|}{$\begin{array}{l}\text { Sarcoplasmic: } \\
\text { fibrillar protein }\end{array}$} \\
\hline & Mean & $\mathrm{SE}$ & Mean & SE & Mean & $\mathrm{SE}$ \\
\hline Ad lib. & $2 \cdot 3$ & 0.01 & 468 & 12 & 0.58 & 0.001 \\
\hline $60 \%$ ad lib. & $1 \cdot 3$ & $0 \cdot 2$ & 283 & 9 & $0 \cdot 7$ & 0.001 \\
\hline $\begin{array}{c}\text { Statistical significance } \\
\text { of difference: } P<\end{array}$ & \multicolumn{2}{|c|}{0.005} & \multicolumn{2}{|c|}{0.001} & \multicolumn{2}{|c|}{ NS } \\
\hline
\end{tabular}

NS, not significant.

* For details of dietary regimen, see p. 142.

marked change with age. The values given in Table 2 mean values for the entire period under study.

\section{DISCUSSION}

It was clear from the results of the present study that undernutrition acted on the muscles by delaying some processes of differentiation. Aspects of fibre histochemistry which had been established before birth, such as myosin ATPase in the biceps brachii and SDH in the soleus muscles, were unaffected.

The metabolic profile of the biceps brachii changed in the perinatal period. Changes in the $60 \%$ of ad lib.-fed group were delayed by approximately 2 weeks. The controlling mechanism for fibre transitions is thought to be weight specific (Ashmore et al. 1972) and is supported by the work presented here. At 2 and 3 weeks in the control and 4 and 5 weeks in the dietary-restricted groups (which is when the transitions occurred) there were no significant differences in body weights.

Goldspink \& Howells (1974) suggested that fibre size was the main determinant of metabolic type. A fibre grows by proliferation of sarcoplasmic and myofibrillar material which increasingly dilutes the mitochondria. They are no longer able to survive on the reduced $\mathrm{O}_{2}$ levels available by diffusion across the cell surface. $\mathrm{O}_{2}$ levels are further eroded by the now inadequate capillary bed (Sillau \& Banchero, 1977). Energy demands are met by a switch to glycolysis, the enzymes for which multiply rapidly. There is, therefore, an inverse relationship between oxidative and glycolytic metabolism (Dubowitz \& Pearce, 1960).

In Table 1 it can be seen that fibre area and body-weight were related. Undernutrition might, therefore, delay metabolic enzyme alterations via body weight. While this explanation holds for the biceps brachii, it seems from the soleus muscle that there was no direct relationship between fibre size and metabolic type. For example, the smallest fibres in the soleus were glycolytic. At the point of conversion (which occurred at the same time in soleus of the two nutritional groups), fibres in the undernourished groups were always smaller than those in the control muscle. The relationship between fibre size and enzyme transformations (at least during differentiation) may be purely a refiection of the immaturity of smaller fibres. The smallest fibres in the soleus muscle were also those with immature myosin ATPase characteristics.

The adult guinea-pig soleus is $100 \%$ myosin ATPase acid stable and alkaline labile. In the present study it was found that AATPase lability was lost before BATPase lability was 
gained in some of the fibres. Alkaline stability is bestowed by fast myosin alkaline light chain 1 and acid stability by slow alkaline light chain 1 (Baldwin, 1984). This suggests that for the period of a few weeks slow and fast myosin types were coexistent in the same fibres. Before the attainment of acid stability at 3 weeks postnatally, some of the fibres were only expressing a fast type of isozyme. Undernutrition did not affect the rate of elimination of basic stability, i.e. the disappearance of fast myosin types (which may have been adult or neonatal). On the other hand, it seemed that there was an effect on the appearance of the mature slow myosin isoform in the undernourished animal.

In the rat soleus muscle, from a prenatal expression of four foetal and neonatal (fl-4) and two adult slow isozymes (SM1 and SM2) which differ in both light and heavy chains, there is a progressive elimination of all but one of the two adult slow isozymes (SM2) (Lyons et al. 1983). In the present study the number of AATPase negative fibres rose in the control muscle at 2 weeks postnatally. This suggested that a slow myosin isoform was briefly lost in some fibres. This might occur by a slight delay between SM1 being suppressed and SM2 being produced in a few of the fibres. For a while, therefore, there was no slow myosin in individual fibres which would be acid labile. In the dietary-restricted soleus muscle there was no such decline in acid-stable fibres. This could be explained simply by SM2 being manufactured before SM1 decreased, i.e. the elimination of SM1 was delayed in the undernourished animals.

It is thought that the progression of fast-type isoenzymes is controlled by thyroid hormone and slow ones by the intervention of tonic innervation (Butler-Browne \& Whalen, 1984). However, it is known that fibres begin differentiating while still polyneuronally innervated (Hoh et al. 1988). Unless nervous input is homogeneous there must be a control which ensures that only one nerve type (i.e. slow or fast twitch) is perceived by the muscle fibre. It has been suggested that load directs fibres to express slow myosin isoforms (Noble et al. 1983). Delaying effects of undernutrition on the appearance of adult slow myosin isoforms might, therefore, be associated with a reduction in body weight.

There was an effect of undernutrition on all biochemical variables measured. Although there must be a gradual increase in total DNA in a given muscle due to satellite cell proliferation (Moss \& Leblond, 1971), a decrease in DNA concentration reflects growth in cell size or tissue volume (Prior et al. 1979; Wigmore, 1982). The general tendency in the present study was for DNA concentration to fall with age after 2-3 weeks, except initially when total DNA was rapidly increasing. The concentration of DNA in the undernourished muscle was higher than that of the control because the cells were smaller. Later, although there was no difference in DNA concentrations between the groups, this is clearly not due to equivalence in fibre size between the groups (note the effects on fibre size in the biceps and soleus muscles). It has already been shown that fibre size reduction is greater than muscle cross-sectioned area reduction in undernourished muscles (Ward, 1989). The extracellular compartment must have diluted the DNA fraction in the malnourished animal to the same extent that increased fibre size reduced concentrations in the control muscle.

RNA concentration increased with age in the control group, whereas in the malnourished muscle it decreased. The low rate of RNA increase in the undernourished semitendinosus was not sufficient to offset the reduction in RNA concentration which would occur with increase in muscle size. Not only was there an apparent effect of undernutrition on transcription but there also appeared to be a reduction in translation. This was seen in the lower total levels of protein in the malnourished muscle.

There was no difference in the extent to which the fibrillar and sarcoplasmic proteins were affected by postnatal malnutrition. Prenatally the structural proteins are more at risk (Aziz-Ullah, 1974; Wigmore, 1982) which leads to a rise in the sarcoplasmic: fibrillar ratio. The difference in the developmental periods is presumably related to the diverse activity of 
the muscle fibres at these times. The fibres are less contractile before birth so the metabolic proteins are preserved at the expense of the myofilaments. Postnatally both components are equally important and their roles are interdependent.

RNA concentration in the control semitendinosus muscle exhibited a change at about 5 or 6 weeks. This is the watershed between the rapid growth phase and a slower growth period. At 5 weeks postnatally guinea-pig weight is only half its adult level, so that maximum muscle size is still to be achieved. However, in the intervening growth period to maturity protein synthesis must be occurring at a lower rate than previously. The greatest increase is sustained by lower rates of protein degradation. Furthermore, 5 weeks may mark the end of a developmental process. The semitendinosus muscle has a mixed-fibre-type population, with many slow oxidative fibres in the deep region of the muscle. It is possible that enzyme transitions similar to those in the soleus muscle were occurring. These enzyme changes were complete by 5-6 weeks postnatally. The achievement of metabolic maturity might coincide with a decline in RNA levels at this time.

To conclude, it has been shown that undernutrition delays the process of metabolic enzyme conversion in the fast-twitch biceps brachii. Myosin ATPase reactions were already mature by the time of birth and were not affected by inadequate nutrition. Conversely, in the soleus muscle there were effects on myosin ATPase properties which can be explained by the fact that these properties were maturing up to 6 weeks postnatally in this muscle. Some of the effects were due to reductions in fibre area, although it was apparent that size was not the only cause. The depression in RNA concentrations and protein:DNA ratios in the $60 \%$ of ad lib.-fed group points to lowered rates of protein synthesis in these animals.

The authors would like to thank Glynn Hammond for help with some of the biochemistry and Catherine Sutton for technical assistance. The work was supported by the Agricultural and Food Research Council.

\section{REFERENCES}

Ashmore, C. R., Addis, P. B. \& Doerr, L. (1972). Postnatal development of muscle fibre types in domestic animals. Journal of Animal Science 34, 37-41.

Aziz-Ullah (1974). Studies on muscle development with specific reference to the effects of protein malnutrition. PhD Thesis, University of Hull.

Baldwin, K. M (1984). Muscle development; neonatal to adult. Exercise and Sport Sciences Reviews 12, 1-19.

Baldwin, K. M., Cambell, P. J., Hooker, A. M. \& Lewis, R. E. (1978). Enzyme changes in neonatal skeletal muscle; effect of thyroid deficiency. American Journal of Physiology 235, 97-102.

Barany, M. (1967). ATPase activity of myosin correlated with speed of shortening. Journal of General Physiology 50, 197-218.

Bedi, K. S., Birzgalis, A. R., Mahon, M., Smart, J. L. \& Wareham, A. C. (1982). Early life undernutrition in rats; I. Quantitative histology of skeletal muscles from underfed young and adult refed animals. British Journal of Nutrition 47, 417-431

Butler-Browne, G. S. \& Whalen, R. G. (1984). Myosin isozyme transitions occurring during the postnatal development of the rat soleus muscle. Developmental Biology 102, 324-334.

Close, R. (1964). Dynamic properties of fast and slow muscles of the rat during development. Journal of Physiology 173, 74-95.

Drachman, P. B. \& Johnson, D. M. (1973). Development of a mammalian fast muscle; dynamic and biochemical properties related. Journal of Physiology 234, $29-43$.

Dubowitz, V. \& Pearce, A. G. E. (1960). Reciprocal relation of phosphorylase and oxidative enzymes in skeletal muscle. Nature 185, 701-702.

Engel, W. K. \& Kaparti, G. (1968). Impaired skeletal muscle maturation following neonatal neurectomy. Developmental Biology 17, 713-723.

Gauthier, G. F., Lowey, S., Benfield, P. A. \& Hobbs, A. W. (1982). Distribution and properties of myosin isozymes in developing avian and mammalian skeletal muscle fibres. Journal of Cell Biology 92, 47-84.

Gauthier, G. F., Lowey, S. \& Hobbs, A. W. (1978). Fast and slow myosin in developing muscle fibres. Nature 274, 25-29.

Goldspink, G. (1962). Biochemical and physiological changes associated with the postnatal development of the biceps brachii. Comparative Biochemistry and Physiology 7, 157-168. 
Goldspink, G. \& Howells, K. F. (1974). Work induced hypertrophy in exercised normal muscles of different ages and the reversibility of hypertrophy after the cessation of exercise. Journal of Physiology 239, 179-193.

Goldspink, G. \& Ward, P. S. (1979). Changes in rodent muscle fibre types during postnatal growth, nutrition and exercise. Journal of Physiology 296, 453-469.

Guth, L. \& Samaha, F. J. (1970). Research note: Procedure for the histochemical demonstration of Actomyosin ATPase. Experimental Neurology 28, 365-367.

Helander, E. (1957). On quantitative muscle protein determination. Sarcoplasm and myofibril protein content of normal and atrophic skeletal muscles. Acta Physiologica Scandinavica 41, Suppl., 141.

Hoh, J. F., Hughes, S., Hugh, G. \& Pozagaj, I. (1988). Three hierarchies in skeletal muscle fibre classification: allotype, isotype and phenotype. UCLA Symposia on Molecular and Cellular Biology Suppl., I2C.

Howells, K. F., Matthews, D. R. \& Jordan, T. C. (1978). Effects of pre and perinatal malnutrition on muscle fibres from fast and slow rat muscles. Research into Experimental Medicine 173, 35-40.

Ianuzzo, C. P., Patel, P., Chen, V.\& O'Brien, P. (1980). A possible thyroidal trophic influence on fast and slow skeletal myosin. In Plasticity of Muscle, pp. 593-606 [D. Pette, editor]. Berlin: de Gruyter.

Lyons, S. E., Kelly, A. M., Rubenstein, N. A. \& Hazelgrove, J. (1983). Myosin transitions in developing fast and slow muscles of the rat hind limb. Differentiation 25, 163-175.

Millward, D. J. (1970). Protein turnover in skeletal muscle. I. The measurement of rates of synthesis and catabolism of skeletal muscle protein using $\left({ }^{14} \mathrm{C}\right) \mathrm{Na}_{2} \mathrm{CO}_{3}$ to label protein. Clinical Sciences 39, 577-590.

Moss, F. P. \& Leblond, C. P. (1971). Satellite cells as the source of nuclei in the muscle of growing rats. Anatomical Record 170, 421-430.

Munro, H. N. \& Fleck, A. (1966). The determination of nucleic acids. Methods of Biochemical Analysis 14, 133-176.

Nachlas, M. M., Tsouk, K., De Sousa, F., Cheng, C. \& Seligman, M. (1957). Cytochemical demonstration of succinic dehydrogenase by the use of a new p-nitrophenol substituted ditetrazole. Journal of Histochemistry and Cytochemistry 5, $420-436$.

Noble, E. G., Dabrowski, B. L. \& Ianuzzo, C. P. (1983). Myosin transformation in hypertrophied sat muscle. Pflügers Archives 396, 260-271.

Peter, J. B., Barnard, R. J., Edgerton, V. R., Gillespie, C. A. \& Stempel, K. E. (1972). Metabolic profiles of 3 fibre types of skeletal muscle in guinea-pigs and rabbits. Biochemistry 11, 2627-2633.

Prior, R. C., Scott, R. A., Lister, D. B. \& Campion, D. R. (1979). Maternal energy status and development of liver and muscle in the bovine foetus. Journal of Animal Science 48, 1534-1545.

Sillau, A. H. \& Banchero, N. (1977). Effect of malnutrition on capillary density, fibre size and composition in rat skeletal muscle. Proceedings of the Society of Experimental and Biological Medicine 154, 461-466.

Stickland, N. C., Widdowson, E. M. \& Goldspink, G. (1975). Effects of severe energy and protein deficiencies on the fibres and nuclei of skeletal muscle of pigs. British Journal of Nutrition 34, 421-428.

Swatland, H. J. (1983). Aerobic activity in the axis of the growing myofibres in the porcine biceps femoris. Journal of Animal Science 56, 1324-1328.

Takeuchi, T. (1956). Histochemical demonstration of phosphorylase. Journal of Histochemistry and Cytochemistry 4, 84 .

Ward, S. S. (1989). The effect of undernutrition on skeletal muscle development and growth in the guinea pig. PhD Thesis, University of London.

Wigmore, P. M. C. (1982). Prenatal muscle development in the pig. PhD Thesis, University of Edinburgh.

Winick, M. \& Nobel, A. (1966). Cellular response in rats during malnutrition at various ages. Journal of Nutrition 89, 300-306. 


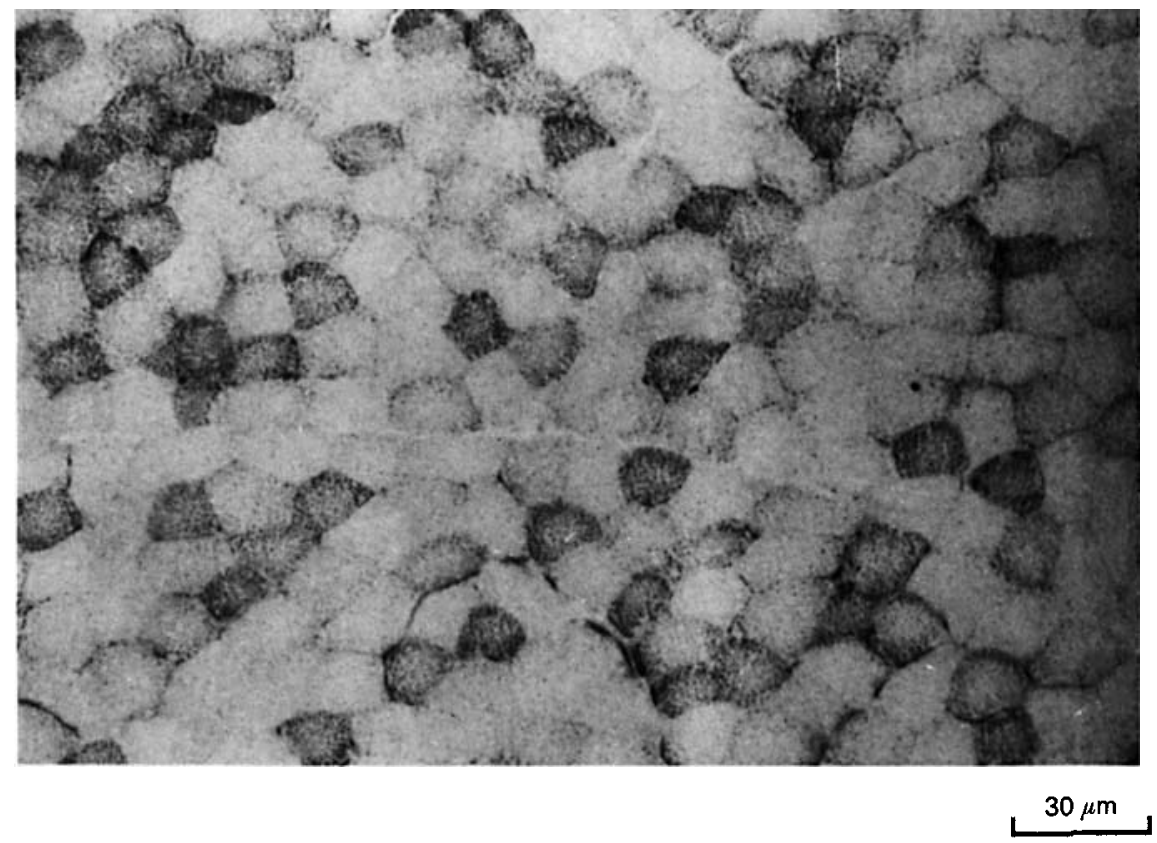

Plate 1. Superficial area of the control guinea-pig biceps brachii reacted for succinate dehydrogenase $(E C 1.3 .99 .1)$ at 6 weeks of age. For details of procedures, see p. 142. 

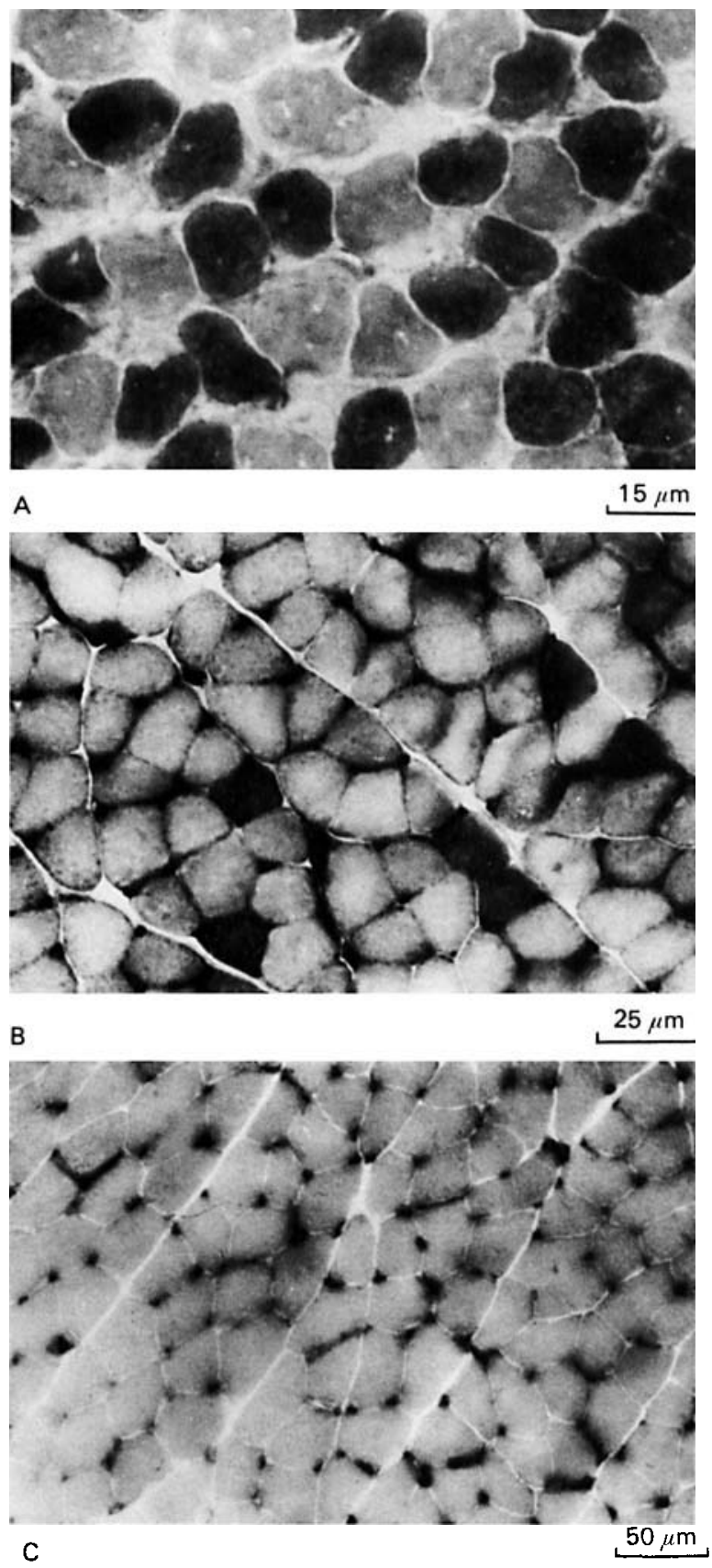

Plate 2. Control guinea-pig soleus reacted for ATPase (EC 3.6.1.32) in a basic medium. (A), neonatal; (B), 5 weeks; (C), 6 weeks. For details of procedures, see p. 142. 